Human

Development

\title{
Acquisition of responses with different effort requirements after exposure to noncontingent stimuli
}

\author{
Carlos Henrique S. da Silva ${ }^{1}$ \\ Dttps://orcid.org/0000-0001-8985-2610 \\ Nilza Micheletto ${ }^{1}$ \\ iD https://orcid.org/0000-0002-5734-5152
}

How to cite this article: Silva, C. H. S., \& Micheletto, N. (2020). Acquisition of responses with different effort requirements after exposure to noncontingent stimuli. Psicologia: Teoria e Prática, 22(3), 161-184. doi:10.5935/1980-6906/psicologia.v22n3p161-184

Submission: 19/07/2019

Acceptance: $24 / 06 / 2020$

The content of Psicologia: Teoria e Prática is distributed under the terms of the Creative Commons Attribution License.

1 Pontifical Catholic University of São Paulo (PUC-SP), São Paulo, SP, Brazil. 


\begin{abstract}
This experiment investigated whether noncontingent appetitive stimuli exposure has effects in a subsequent response acquisition with different efforts. On the first phase, rats were exposed to contingent events to nose poke response, noncontingent events, or no exposition. On the second phase, the bar press response of the animals was continuously reinforced or submitted to a FR3 schedule. The time and number of reinforcers to response acquisition varied among subjects, and none relation was identified between first phase exposition with response acquisition of different efforts on phase 2 . The longest time in response acquisition identified in some subjects occurred due to competitive responses on the first phase followed by appetitive stimuli. Possibilities for future studies and possible implications for the applied context are discussed.
\end{abstract}

Keywords: learned helplessness; noncontingent appetitive stimuli; response independent events; contiguity; response competition.

\title{
AQUISIÇÃO DE RESPOSTAS DE DIFERENTES CUSTOS APÓS EXPOSIÇÃO A ESTIIMULOS NÃO CONTINGENTES
}

\section{Resumo}

Este experimento investigou se a exposição a estímulos apetitivos não contingentes tem efeitos sobre a aquisição de respostas de diferentes custos. Na fase 1 , ratos foram expostos a eventos contingentes às respostas de focinhar, eventos não contingentes ou não foram expostos. Na fase 2, a resposta de pressão à barra dos animais foi reforçada continuamente ou em esquema FR 3. O tempo e o número de reforçadores para aquisição de respostas variaram entre os sujeitos, não sendo identificada relação entre a exposição na fase 1 e o custo da resposta a ser adquirida na fase 2.0 maior tempo para aquisição da resposta ocorreu possivelmente por causa de respostas competitivas acidentalmente seguidas por estímulos apetitivos na fase 1 . Discutem-se possibilidades para estudos futuros e possíveis implicações para o contexto aplicado.

Palavras-chave: desamparo aprendido; estímulos apetitivos não contingentes; eventos independentes da resposta; contiguidade; competição de respostas. 


\title{
ADQUISICIÓN DE RESPUESTAS DE DIFERENTES COSTOS DESPUÉS DE LA EXPOSICIÓN A ESTÍMULOS NO CONTINGENTES
}

\begin{abstract}
Resumen
Este experimento investigó si la exposición a estímulos apetitivos no contingentes tiene efectos en la adquisición de respuestas a diferentes costos. En la fase 1 se expusieron ratones a eventos contingentes a las respuestas del hocico, eventos no contingentes o no fueron expuestos. En la fase 2 la respuesta de presión a palanca de los sujetos se reforzó continuamente o en FR 3. El tiempo y el número de reforzadores para adquirir respuestas variaron entre los sujetos de las diferentes condiciones sin que se identificara ninguna relación entre la exposición de la fase 1 y el costo de la respuesta a ser adquirida. El tiempo más largo para obtener la respuesta de algunos sujetos posiblemente se debió a respuestas competitivas que, en la fase 1 , fueron seguidas por estímulos apetitivos. Se discuten posibilidades para estudios futuros y posibles implicaciones para el contexto aplicado.

Palabras clave: desamparo aprendido; estímulos apetitivos no contingentes; eventos independientes de respuesta; contigüidad; competencia de respuestas.
\end{abstract}

\section{Introduction}

One characteristic of the three-term contingency is the dependent relationship between responses and events in the environment. In addition, the concept of contingency implies the probability of an event occurring given the presence of a response. In a contingency, the event occurs after the response, with or without contiguity (juxtaposition of events in time). When the event occurs independently from the emission of a response, we say that the relationship between events is merely contiguous (Baum, 2017).

Skinner (1948) demonstrates the effects of the independent relationship between the response and contiguous events in an experiment, in which a pigeon received food every 15 seconds, regardless of any response. This established responses, such as quickly turning or twisting. Skinner (1948) labeled the selected responses as "superstitious" behavior. After the identification of superstitious behavior, researchers conducted studies involving the phenomenon (or noncontingent schedules) and found that the contiguity between events could be sufficient for the selection of responses followed by noncontingent events (e.g., Cardoso, Britto, \& Simonassi, 2016). 
Maier and Seligman (2016) highlight different results, pointing to a group of studies that evaluated the effects of exposure to noncontingent events on the acquisition of behavior in future situations. The triadic design is presented as the experimental model to study these effects. In this model, the experiment is generally divided into two phases involving three groups of subjects. Traditionally, in phase 1 , the subjects from the escape group (contingent) receive electric shocks on the cage floor that can be turned off by a response (e.g., pressing a panel for dogs and pressing a lever for rats). The no escape group (noncontingent) is yoked to the escape group, so that they receive shocks in the same instances, intensities and of the same durations, with the difference being that no response can turn off the shock. The control group does not undergo this phase. In phase 2, subjects from all groups are individually placed in an experimental box, in which shocks are given and can be turned off when the subject jumps from one chamber to another.

Phase 1 results for the contingent group show that the latency between the start of the shock and the analyzed response decreases throughout the phase. For the subjects that cannot turn off the shocks, the latencies remain high during the entire phase, and the subjects stop responding. In phase 2, the contingent and control groups learn the escape response. However, the group exposed to noncontingent aversive stimuli do not. The difficulty in learning a response, after exposure to noncontingent aversive stimuli, is called "learned helplessness" (Maier \& Seligman, 2016).

Different hypotheses for the phenomenon have been discussed in the literature. Learned helplessness (Maier \& Seligman, 2016) establishes that the subject learns, during exposure to uncontrollable events, the independent relationship between its responses and environmental events, which interferes in the acquisition of an operant response. Glazer and Weiss (1976) write of learned inactivity: "a pattern of low activity that is selected by accidental contingencies in phase 1 and is incompatible with the pattern of responses to be learned in phase 2." On the other hand, Hunziker and Gehn (2010) try to explain the effects by suggesting that previous exposure to noncontingent stimuli in phase 1 can interfere with later performance depending on the time between response and consequence in phase 2. Specifically, helplessness is more probable the longer the time between the emission of the operant response and the consequence and is less probable the shorter the time (Hunziker \& Gehm, 2010). 
Following research with aversive stimuli, Engberg, Hansen, Welker, and Thomas (1972) investigated the possibility of producing the same effects by exposing pigeons, distributed into groups under the triadic design, to non-aversive, noncontingent (appetitive) stimuli and evaluate the effects on the acquisition of an operant response. They identified that the subjects exposed to noncontingent stimuli needed more trials to learn the response, showing the possible generality of learned helplessness.

Later studies tried to produce effects like learned helplessness by using appetitive stimuli. Some reported delayed acquisition of the operant response after exposure to noncontingent appetitive stimuli (e.g., Job, 1988; Oakes, Rosenblum, \& Fox, 1982; Welker, 1976), while others did not (e.g., Beatty \& Maki, 1979; Schwartz, Reisberg, \& Vollmecke, 1974). Despite the relevance of understanding the possible effects of exposure to noncontingent appetitive stimuli on the acquisition of new responses, we did not find studies conducted after the 1990s that confirmed the generality of these effects obtained with aversive stimuli.

Among the studies that did not report consistencies, Schwartz et al. (1974) investigated the presence and absence of the manipulandum in phases 1 and 2 and identified that the delay effect is more likely when the manipulandum is absent in phase 2, and Beatty and Maki (1979) manipulated different quantities of noncontingent appetitive stimuli in phase 1 , but the data did not show differences in later response acquisition.

Among the studies that reported consistencies stands that of Oakes, Rosenblum, and Fox (1982). In it, the authors controlled the quantity of food given to the contingent, noncontingent and control groups in phase 1 . In phase 2 , all groups were given lever-press training with a retractable lever, and learning took longer for the group that had received noncontingent stimuli. Job (1988) manipulated the presence and absence of the manipulandum between phases, as well as continuous and intermittent reinforcement in phase 1 for the contingent group. It took longer for subjects to learn the operant response regardless of continuous or intermittent reinforcement in phase 1 when: 1 . the manipulandum in phase 2 was present in phase 1 ; and 2 . the manipulandum in phase 1 was absent in phase 2 .

An analysis of these studies showed that experimental manipulation has mainly occurred in phase 1 and that continuous reinforcement (CRF) has generally 
been used in phase 2. Alternatively, Welker (1976) manipulated response effort in phase 2 to verify its effect on response acquisition. Welker (1976) divided the pigeons into three groups: contingent, noncontingent and control. In phase 1 for the contingent group, pressing a treadle was reinforced in a variable interval schedule (VI 15s, 30s, 45s), while, for the noncontingent group (not yoked), food was dispensed in a variable time schedule (VT 15S, 30s and 45s). The control group only underwent hopper training. In phase 2 , all three groups produced food in CRF by pecking at a key. The time taken to obtain the first 50 reinforcers was greater for the noncontingent group. In the second experiment, the author tested different response efforts using a fixed ratio schedule (FR3) in phase 2. More time elapsed during the first 50 reinforcers in FR as compared the use of CRF. In both experiments, the same amount of time was spent obtaining the last 50 reinforcers, indicating the transience of the effect.

Another study that used FR 3 in phase 2 was that of Beatty and Maki (1979). Although the authors did not directly investigate response effort, they used, in phase 2, a schedule that, according to Welker (1976), increases response effort. Results showed that the time required to acquire reinforcers did not differ significantly between the groups.

Considering the contrasting results regarding the effects of response effort in phase 2 and the fact that only Welker (1979) compared different response efforts, the present study aimed to verify the effect of exposure to noncontingent appetitive stimuli on the later acquisition of responses with different effort requirements. Unlike in Welker (1976), the present study used rats as experimental subjects and a triadic design, yoking subjects from the noncontingent group to those of the contingent group.

Aside from identifying variables that could explain the divergent results of past studies, an experiment investigating the effects of exposure to noncontingent appetitive stimuli on the later acquisition of a response with different effort requirements could have practical implications. Applied studies about socially relevant behaviors usually indicate the effectiveness of exposure to noncontingent events to reduce problem behaviors (Moore, Robinson, Coleman, Cihak, \& Park, 2016; Phillips, lannaccone, Rooker, \& Hagopian, 2017; Rooker, Bonner, Dillon, \& Zarcone, 2018). The effects of this procedure on a subsequent task, however, are still not clear, because basic experimental research using appetitive stimuli have 
yielded inconsistent results (e.g., Beatty \& Maki, 1979; Job, 1988; Oakes et al., 1982; Schwartz et al., 1974; Welker, 1976). Basic research about this topic could serve as a basis for future translational studies.

\section{Method}

\subsection{Subjects}

Eighteen male Wistar rats were used, with ages ranging from 90 to 120 days at the start of the experiment. All were maintained in individual cages under water restriction regimen, so that, during the experiment, they were 80 to $85 \%$ of their ad libitum weight. The project (No. 0012-15) was approved by the Ethics Committee of the Faculty of Human Sciences and Health of the Pontifical Catholic University of São Paulo (PUC-SP).

\subsection{Equipment}

Three operant conditioning chambers measuring $25.5 \times 32 \times 26 \mathrm{~cm}$ (height, width, and depth, respectively) contained within wooden boxes for acoustic insulation $(47 \times 67 \times 47,5 \mathrm{~cm}$ ) were used in both phases. The chambers were equipped with a water dispenser positioned at the center of the right wall.

In phase 1, a nose-poke device was located $6 \mathrm{~cm}$ from the floor and to the left of the water dispenser and contained a circular opening with a $2.5 \mathrm{~cm}$ diameter, in which the subject needed to insert its nose to a depth of at least $1.5 \mathrm{~cm}$ to intersect an infrared beam and for a nose poke response to be registered. In phase 2, a $4.5 \mathrm{~cm}$ long and $2.5 . \mathrm{cm}$ deep lever was installed $7 \mathrm{~cm}$ from the floor and to the right of the water dispenser. A CE AE25 camera linked to a VD 4S 120 ST Digital Video Recorder (DVR) filmed the sessions.

\subsection{Procedure}

Subjects were grouped in triads and allocated to one of six conditions: contingent continuous reinforcement $(\mathrm{CRF}-\mathrm{C})$, contingent fixed ratio (FR-C), noncontingent continuous reinforcement ( $\mathrm{CRF}-\mathrm{NC})$, noncontingent fixed ratio (FR-NC), control continuous reinforcement $(\mathrm{CRF}-\mathrm{CT})$ and control fixed ratio $(\mathrm{FR}-\mathrm{CT})$. 


\subsection{Phase 1: exposure to contingent/noncontingent appetitive stimuli}

In this phase, the differences in procedure only occurred between the contingent, noncontingent and control conditions. In the contingent conditions ( $C R F-C$ and $F R-C$ ), no shaping procedure was used, and, after the water dispenser training, nose-poking responses were followed by water until the subjects emitted 100 responses. In subsequent sessions, a variable interval schedule was in effect (VI $15 \mathrm{~s}, \mathrm{VI} 30 \mathrm{~s}$, and VI 45s, in that order), with ten values in each VI. The criteria for ending sessions in which VI 15s was in effect was 100 reinforcers or 50 elapsed minutes. To switch to another VI value and to conclude phase 1 , the following criteria had to be met: 1 . the total number of responses for each contingent subject in the last three sessions with the same VI value could not vary more than $10 \% ; 2$. all six subjects in the contingent conditions had to meet the first criteria in the same session in order to even out exposure to the same number of sessions.

After the water dispenser training, each subject in the noncontingent conditions (CRF-NC and FR-NC) was yoked to one from the contingent condition. In this manner, every time a response from a contingent subject was reinforced, water was also dispensed to their noncontingent pair, regardless of any response. Nose-poking responses did not have any programmed consequences. The contingent pair determined session and phase termination. Control subjects (CRF$\mathrm{CT}$ and $\mathrm{FR}-\mathrm{CT}$ ) only underwent water dispenser training.

\subsection{Phase 2: operant response acquisition}

The nose-poke device was removed from the left side of the water dispenser, and the lever was placed on its right side. No shaping took place. The differences in procedures occurred in the reinforcement schedule for lever presses, with CRF and FR. The first session took place 24 hours after the end of the first phase, and the second, 48 hours. Sessions were terminated after subjects obtained 100 reinforcers or when 50 minutes had elapsed. The experiment ended after two sessions. The subjects' responses in the CRF conditions ( $C R F-C, C R F-N C$, and CRF$\mathrm{CT}$ ) were reinforced continuously (CRF). The subjects' first response in the FR conditions (FR-C, FR-NC, and FR-CT) was reinforced, and subsequent responses were reinforced in a fixed ratio (FR 3 ). 


\subsection{Video analysis and interobserver agreement}

To check whether noncontingent stimuli could have strengthened responses that preceded them, video recordings of the last session from phase 1 and the first session of phase 2 were analyzed for yoked subjects. These sessions were divided into 10-second blocks, and the following was recorded: 1. the occurrence of responses within each 10-second block; 2 . the response that preceded the presentation of the appetitive noncontingent stimulus by 1 second. The first session of phase 2 for the contingent subjects was also analyzed to investigate; 3 . the possibility of responses selected in phase 1 being emitted in phase 2 . An independent observer analyzed the same footage of both sessions, and the agreement index was calculated using the formula (Agreement/[Agreement + Disagreement] x 100 (Saini, Fisher \& Pisman, 2017). The indexes varied in 1 . between $86 \%$ and $97 \%$; 2 . between $93 \%$ and $100 \%$; and 3. between $91 \%$ and $98 \%$.

\section{Results}

Response effort, differentiated by the CRF and FR 3 schedules, was analyzed as a possible variable that interferes in the acquisition of responses after exposure to noncontingent appetitive stimuli. The first and second columns in Figure 3.1 show the cumulative frequency curves for lever presses reinforced in CRF in phase 2 by the triad subjects from the contingent (dotted lines) - CRF-C, noncontingent (continuous lines) - CRF-NC, and control conditions (dash-dotted lines) - CRF$\mathrm{CT}$. The third and fourth columns of the same figure show lever presses by subjects of the FR 3 conditions (contingent - FR-C, noncontingent - FR-NC and control - FR-CT). Columns one and three refer to the first session, and columns two and four, to the second. 

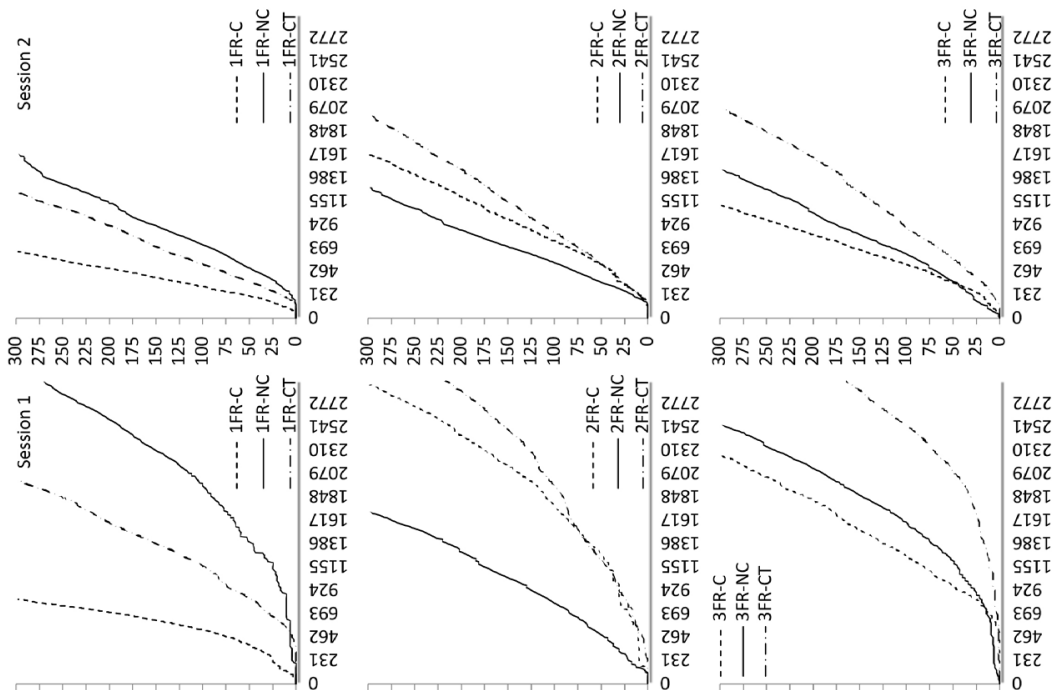

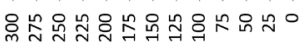

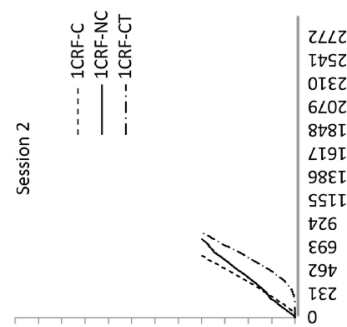

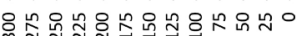

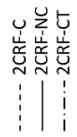

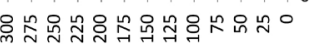
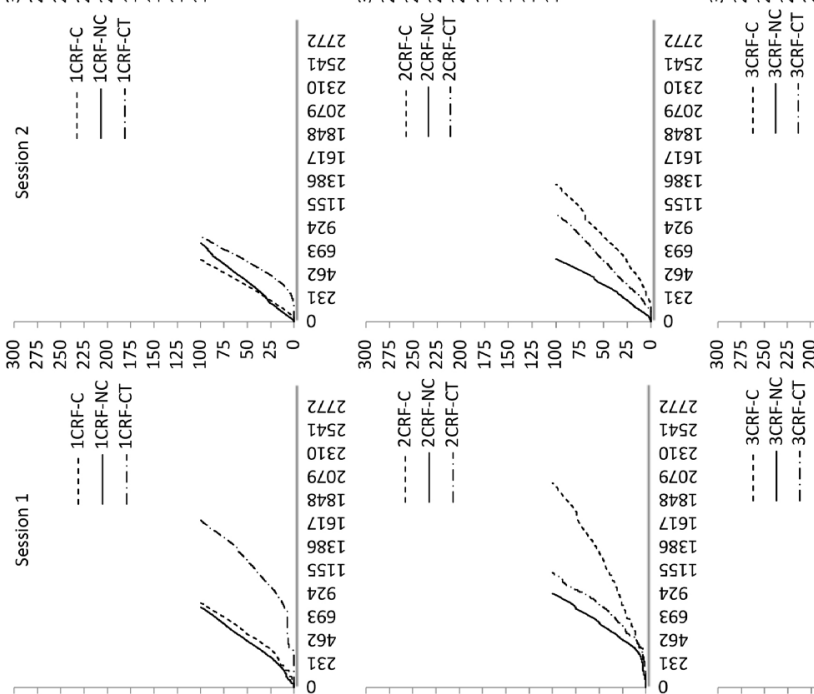

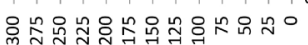
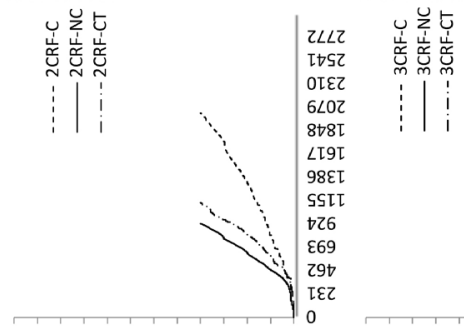
In the first session, the lever-press response was selected for the subjects exposed to CRF (Figure 3.1, first column). 1CRF-NC and 2CRF-NC, which were exposed in phase 1 to noncontingent stimuli, started and ended the session in less time and produced more accelerated curves than the other subjects of their respective triads. In the third triad, $3 \mathrm{CRF}-\mathrm{NC}$ took longer than the other subjects in the CRF conditions to start the task and to acquire the lever-press response. After response acquisition, its cumulative frequency curve shows a slightly higher acceleration than those of the rest of its triad. In sum, among the noncontingent CRF subjects, only one required more time than the others to acquire the response.

As for the other subjects from the contingent continuous reinforcement condition, Figure 3.1 shows different performances. Subject $1 \mathrm{CRF}-\mathrm{C}$, in the first session of phase 2 , took slightly more time to finish the session, and its cumulative frequency curve shows slightly less acceleration than that of $1 \mathrm{CRF}-\mathrm{NC}$. This section of data appears to repeat itself in the first half of the second session. Subject 2CRFC's performance produced the least accelerated curve in the triad in both phase 2 sessions. Subject $3 \mathrm{CRF}-\mathrm{C}$ had the fastest performance of its triad in the first session, producing a curve with higher acceleration than the others, but, in the following session, required more time to acquire the response. As for the control CRF subjects, only one (1CRF-CT) produced a lower acceleration curve and required more time to start and finish sessions compared to its triad, seeing as how the others ( $2 \mathrm{CRF}-\mathrm{CT}$ and $3 \mathrm{CRF}-\mathrm{CT}$ ) were second in completing the session in their respective triads. These data indicate that, in continuous reinforcement, there were no consistencies regarding time for response acquisition, depending on the type of exposure in phase 1. Only one subject exposed to noncontingent stimuli in phase 1 (3CRF-NC) took more time to acquire the lever-press response.

In the FR conditions (third and fourth columns), among the subjects exposed to noncontingent stimuli in phase 1 , only subject $1 \mathrm{FR}-\mathrm{NC}$ required more time to acquire the response. It presented several pauses in activity, a less accelerated curve than the others and did not obtain all reinforcers by the end of the session. Subject 2FR-NC started and finished the task before the other two subjects from its triad. Subject 3FR-NC took longer to conclude the session than the subject exposed to the contingent condition ( $3 F R-C$ ). Subjects $1 F R-C$ and $3 F R-C$, exposed to the contingent condition, presented the curves with the highest acceleration in their triads. The curve for $2 \mathrm{FR}-\mathrm{C}$ was less accelerated only in comparison to its 
yoked pair. From the control condition, 2FR-CT and 3FR-CT had the least accelerated curves within their triads and finished the first session without obtaining 100 reinforcers. As for $1 \mathrm{FR}-\mathrm{CT}$ 's curve, its acceleration was lower than that of the contingent subject and higher than that of the yoked partner.

In the second session (fourth column), all triads obtained all reinforcers and finished the sessions in the same order. The curves show higher acceleration for all subjects, and there is less of a distinction between subjects of the same triad and between triads. One can say that, as in the continuous reinforcement conditions, the subjects exposed to FR3 in phase 2 also presented varied performances regardless of the treatment in phase 1 . Furthermore, only one subject exposed to noncontingent stimuli (1FR-NC) took longer to acquire the lever-press response.

Another measure we evaluated was the time taken to acquire reinforcers (1, 1 to 10,11 to 50, 51 to 100, and o to 100 reinforcers), as shown in Figure 3.2, for subjects in the CRF (first and second columns) and FR conditions (third and fourth columns) in both phase 2 sessions. Arrows with numbers in the third column indicate the number of reinforcers obtained by subjects $1 F R-N C, 2 F R-C T$ and 3FR$\mathrm{CT}$, whose sessions were terminated due to the time limit criteria.

The biggest difference between all subjects in the CRF condition can be seen in the third triad. Noncontingent subject 3CRF-NC required more time to obtain the first reinforcer and to conclude the first session when compared to the other noncontingent subjects. It was also one of the subjects that took the longest in obtaining ten reinforcers. In triads 1 and 2, 1CRF-NC and 2CRF-NC were the fastest in obtaining all reinforcers in the first session. In the control condition, $1 C R F-C T$ required the most time to obtain all reinforcers. In triad 2, contingent subject $2 \mathrm{CRF}-\mathrm{C}$ took longer to acquire reinforcers 11 to 50 and 51 to 100, as well as to finish the session. Data from the second session for triads 2 and 3 are similar: $2 \mathrm{CRF}-\mathrm{C}$ and $3 \mathrm{CRF}-\mathrm{C}$ remain longer in the session, and $2 \mathrm{CRF}-\mathrm{NC}$ and $3 \mathrm{CRF}-\mathrm{NC}$ required less time. These data suggest that, in CRF, time spent on acquiring reinforcers in phase 2 did not appear to depend on the treatment in phase 1. 

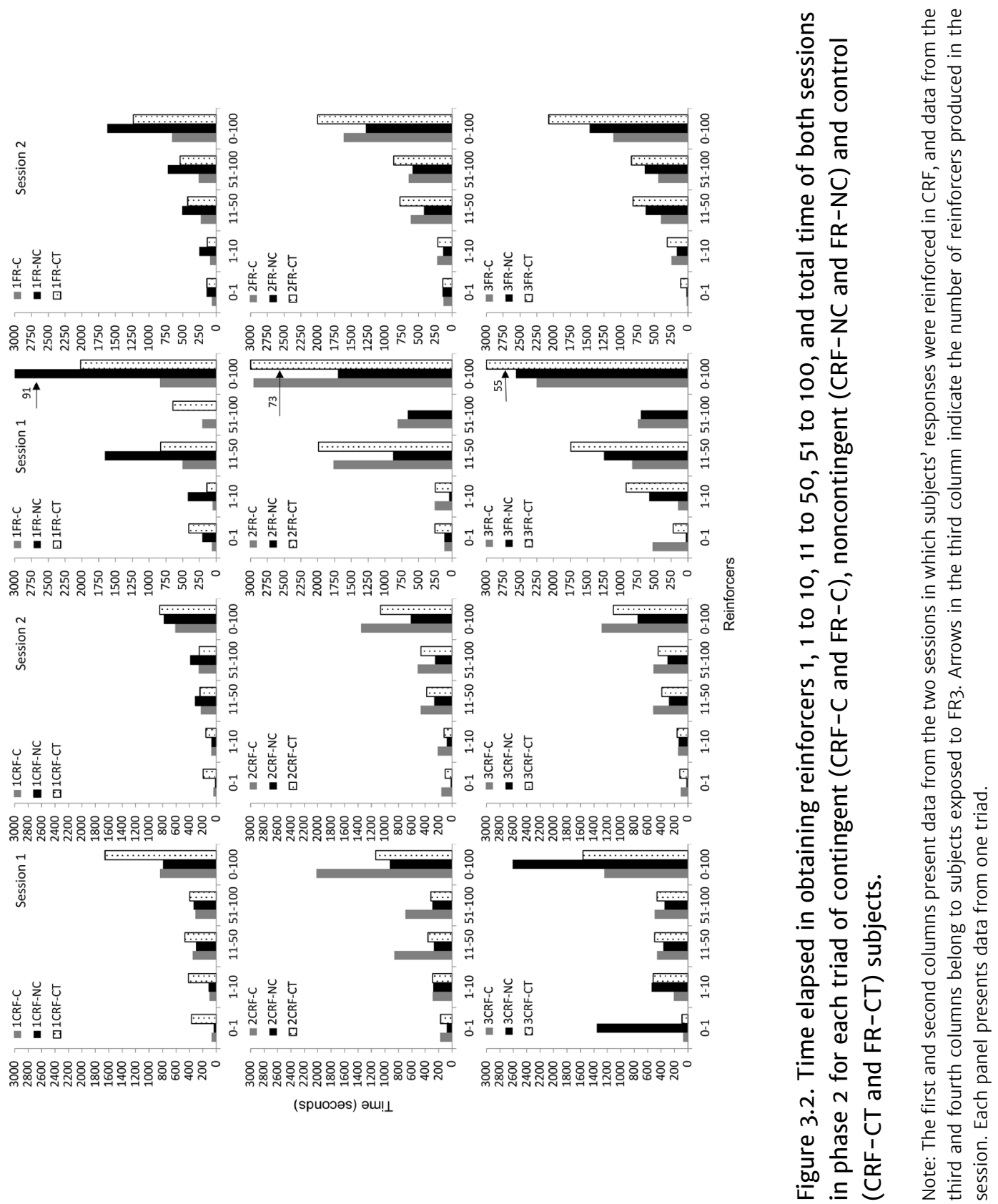

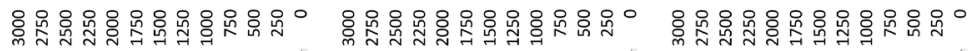

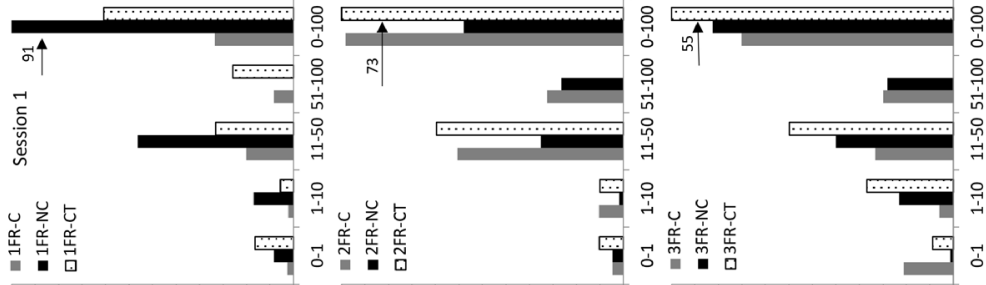

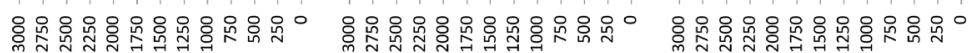

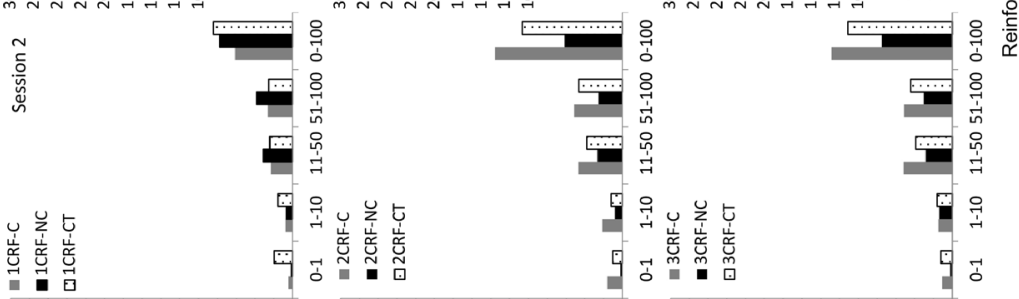

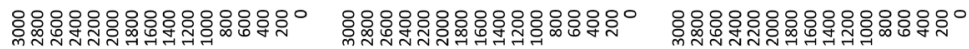

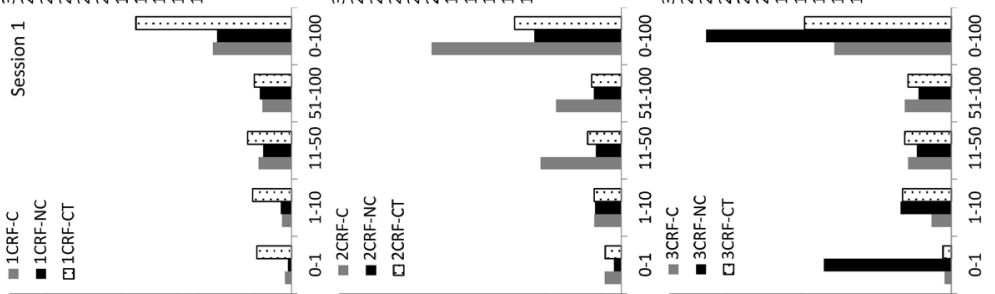

ㅇ్ㅆ

(spuoวəs) əщ!। 
In the first session, for subjects exposed to the FR3 reinforcement schedule (columns 3 and 4), 1FR-NC took longer to obtain reinforcers ( 1 to 10, 11 to 50), compared to others in its triad, and obtained only 91 out of 100 reinforcers. It also required more time in the second session than others in its triad. In comparing the delayed performance by the CRF subject (3CRF-NC) to that of the FR subject (1FR$\mathrm{NC}$ ) in the context of their respective triads, we see that $3 \mathrm{CRF}-\mathrm{NC}$, while taking longer than its group members, still managed to produce the maximum amount of reinforcers before the 50-minute time limit. On the other hand, 1FR-NC reached the time limit and failed to produce all 100 reinforcers.

The other triads produced different data, showing that the control subjects were the ones that required more time to obtain 100 reinforcers. In triad 2, 2FR-CT only obtained 73 reinforcers, and 3FR-CT, from triad 3, only obtained 55 during the first session. In the second session, both in the CRF and FR conditions, all subjects obtained 100 reinforcers, and differences between members of the triads were less noticeable.

In short, the analysis of the time elapsed in obtaining reinforcers, as well as that of the lever-press response curves, show a lack of consistency between time for response acquisition in phase 2 and the different stimulus exposures in phase 1. Exposure to contingent and noncontingent stimuli and non-exposure in phase 1 , as well as the manipulation of response effort in phase 2, did not lead to consistent conclusions, since only one noncontingent subject that was exposed to CRF (3CRF$\mathrm{NC}$ ) and one that was exposed to FR3 (1FR-NC) took longer to acquire the leverpress response than other in their respective triads. Therefore, the effect of exposure to noncontingent appetitive stimuli on subsequent response acquisition involving different response efforts was not observed.

Videos of the last session of phase 1 were analyzed to verify whether, for subjects taking longer in obtaining reinforcers, responses could have been acquired due to being followed by noncontingent events, which would have competed with lever presses in phase 2. Table 3.1 shows the number of responses emitted by subjects in the noncontingent conditions in the last session of phase 1 , the first session of phase 2, and the total temporal contiguity between response and noncontingent appetitive stimulus in phase 1. 
Table 3.1. Number of responses (No. R) emitted by subjects in the noncontingent conditions in the last session of phase $1\left(\mathrm{P}_{1}\right)$, first session of phase $2\left(\mathrm{P}_{2}\right)$, and the total number of temporal contiguities of up to 1 second (C) between response and noncontingent appetitive stimulus in phase 1.

\begin{tabular}{|c|c|c|c|c|c|c|c|c|c|c|c|c|c|c|c|}
\hline \multirow[b]{2}{*}{ 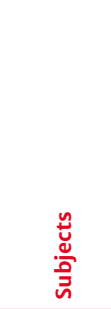 } & \multirow[b]{2}{*}{ 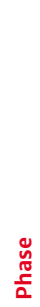 } & \multirow[b]{2}{*}{ 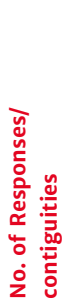 } & \multicolumn{13}{|c|}{ Responses } \\
\hline & & & 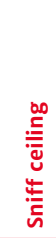 & 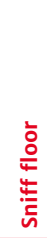 & . & $\begin{array}{l}\overline{\bar{\pi}} \\
\sum^{2} \\
\text { 屶 } \\
\text { ñ }\end{array}$ & 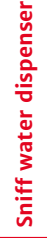 & 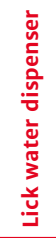 & $\frac{y}{\frac{1}{\pi}}$ & $\begin{array}{l}\varepsilon \\
\text { 옹 }\end{array}$ & 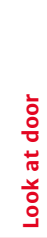 & $\begin{array}{l}\stackrel{0}{\circ} \\
\text { 을 }\end{array}$ & 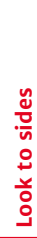 & 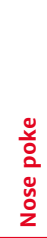 & $\begin{array}{l}\bar{\pi} \\
\stackrel{0}{\circ}\end{array}$ \\
\hline \multirow[t]{3}{*}{$1 \mathrm{CRF}-\mathrm{NC}$} & $\mathrm{P} 1$ & $\mathrm{~N}^{\circ} \mathrm{R}$ & 140 & 23 & o & 5 & 0 & 299 & 29 & 5 & 127 & 0 & 0 & 25 & 653 \\
\hline & & C & 4 & 5 & 0 & 0 & 0 & 46 & 0 & 1 & 7 & 0 & 0 & 0 & 63 \\
\hline & $\mathrm{P} 2$ & $\mathrm{~N}^{\circ} \mathrm{R}$ & 3 & 0 & 0 & 3 & 0 & 6 & 1 & 1 & 2 & $\mathrm{O}$ & 0 & 0 & 16 \\
\hline \multirow[t]{3}{*}{$2 \mathrm{CRF}-\mathrm{NC}$} & $\mathrm{F} 1$ & $N^{\circ} \mathrm{R}$ & 10 & 233 & 0 & 1 & 0 & 306 & 46 & 17 & 9 & 0 & 7 & 7 & 629 \\
\hline & & C & 0 & 30 & 0 & 0 & 0 & 30 & 1 & 1 & 0 & 0 & 3 & 0 & 65 \\
\hline & $\mathrm{P}_{2}$ & $\mathrm{~N}^{\circ} \mathrm{R}$ & 6 & 10 & 0 & 4 & 3 & 12 & 4 & 3 & 3 & 0 & 1 & 0 & 46 \\
\hline \multirow[t]{3}{*}{$3 \mathrm{CRF}-\mathrm{NC}$} & $\mathrm{P} 1$ & $\mathrm{~N}^{\circ} \mathrm{R}$ & 57 & 138 & 47 & 60 & 23 & 246 & 47 & 14 & 3 & 15 & 0 & 5 & 655 \\
\hline & & C & 6 & 12 & 3 & 3 & 1 & 34 & 1 & 2 & 1 & 1 & $\mathrm{O}$ & $\mathrm{O}$ & 64 \\
\hline & $\mathrm{P} 2$ & $N^{\circ} \mathrm{R}$ & 38 & 84 & 45 & 14 & 9 & 54 & 18 & 8 & 1 & 6 & 0 & $\mathrm{O}$ & 277 \\
\hline \multirow[t]{3}{*}{ 1FR-NC } & $\mathrm{P} 1$ & $N^{\circ} \mathrm{R}$ & 85 & 83 & 0 & 25 & 38 & 272 & 69 & 6 & 56 & 19 & 15 & 1 & 669 \\
\hline & & C & 8 & 5 & 0 & 1 & 3 & 38 & 3 & 0 & 5 & o & 1 & $\mathrm{o}$ & 64 \\
\hline & $\mathrm{P} 2$ & $N^{\circ} \mathrm{R}$ & 46 & 30 & 0 & 17 & 23 & 116 & 17 & 5 & 6 & 3 & 0 & 0 & 263 \\
\hline \multirow[t]{3}{*}{ 2FR-NC } & $\mathrm{P} 1$ & $N^{\circ} \mathrm{R}$ & 3 & 9 & 0 & 14 & 4 & 319 & 13 & 12 & 16 & 0 & 42 & 0 & 432 \\
\hline & & C & 0 & 0 & 0 & 1 & 0 & 56 & 0 & 2 & 2 & 0 & 2 & 0 & 63 \\
\hline & $\mathrm{P} 2$ & $\mathrm{~N}^{\circ} \mathrm{R}$ & 3 & 6 & 0 & 5 & 2 & 5 & 5 & 1 & 0 & 0 & 0 & 0 & 27 \\
\hline \multirow[t]{3}{*}{$3 \mathrm{FR}-\mathrm{NC}$} & $\mathrm{P} 1$ & $N^{\circ} \mathrm{R}$ & 134 & 136 & 0 & 24 & 45 & 273 & 59 & 17 & 2 & 0 & 13 & 138 & 841 \\
\hline & & C & 10 & 13 & 0 & 2 & 0 & 32 & 2 & 2 & 0 & 0 & 2 & 2 & 65 \\
\hline & $P_{2}$ & $\mathrm{~N} \circ \mathrm{R}$ & 45 & 46 & 0 & 18 & 27 & 58 & 20 & 3 & 0 & 0 & 0 & 0 & 217 \\
\hline
\end{tabular}

All noncontingent subjects emitted a high number of responses in the last phase 1 session. Despite the low emission of nose pokes, subjects emitted other responses before the appetitive stimulus was dispensed. Some had a higher frequency than others: sniffing the ceiling (134 times for 3FR-NC), sniffing the floor (233, 138, 83 and 136 for 2CRF-NC, 3CRF-NC, 1FR-NC and 3FR-NC, respectively).

Almost all responses with higher frequencies in the previous session (phase 1) continued to be emitted at the start of phase 2 for all noncontingent subjects. 
However, in phase 2, subjects that required more time (Figure 3.2) to acquire the lever-press response ( $3 \mathrm{CRF}-\mathrm{NC}$ and $1 \mathrm{FR}-\mathrm{NC}$ ) emitted a greater number of other responses compared to the faster noncontingent subjects from their triads (1CRFNC, 2CRF-NC and 2FR-NC). In phase 2, subjects 3CRF-NC and 1FR-NC emitted, respectively, 277 and 263 responses other than lever presses. On the other hand, $1 \mathrm{CRF}-\mathrm{NC}, 2 \mathrm{CRF}-\mathrm{NC}$, and 2FR-NC emitted, respectively, 16, 46, and 27 responses.

The data seem to indicate a response pattern that had been, at least at the start of the first session in phase 2 , competing with the lever-press response, which explains why some subjects required more time for response acquisition. Perhaps, in phase 2, the time involved in emitting responses that had been, at some point, accidently followed by noncontingent appetitive stimuli at the end of phase 1 (Table 3.1) and certain response topographies (sniffing the ceiling or floor, licking the water dispenser) initially prevented the emission of lever presses (Figure 3.1).

According to Table 3.1, these subjects emitted between 629 (1CRF-NC, 653; 2CRF-NC, 629; 3CRF-NC, 655; 1FR-NC, 669) and 841 (3FR-NC) responses in the last session of phase 1 . In phase 2 , the subjects that took the longest to systematically press the lever (3CRF-NC, 1800" and 1FR-NC, 898", approximately) were those that had emitted a greater number of responses (277 and 263, respectively) with high contiguity in the previous phase when compared to the others. One can assume that the total number of responses other than lever presses, emitted by both subjects, competed with lever presses, which consequently took longer to be selected. The other subjects that were first in finishing the session within their triads took less time to emit and acquire the lever-press response (1CRF-NC, 39"; 2CRF-NC, 81"; 2FR-NC, 116"). The fact that these subjects emitted a smaller number of other responses in phase $2(15,46$, and 27 , respectively) could have influenced the faster emission and selection of lever presses. Subject 3FR-NC emitted 217 responses in phase 2 - a little less than the noncontingent subjects that took longer in their triads - and acquired the lever-press response after the contingent subject and before the control in the triad. However, in contrast to the latter, 3FR-NC required the least amount of time to press the lever and produce the first reinforcer (34") when compared to other noncontingent subjects (1CRF-NC, 39"; 2CRF-NC, 81"; 3CRF-NC, 1356"; 1FR-NC, 66"; 2FR-NC, 116").

It is also possible that, for contingent subjects, responses in phase 1 delayed responses in phase 2 , seeing as some subjects in phase 2 were not the first to finish 
the task ( $1 \mathrm{CRF}-\mathrm{C}, 2 \mathrm{CRF}-\mathrm{C}$ and $2 \mathrm{FR}-\mathrm{C}$ ), which is generally expected in studies with aversive stimuli. In phase 2 , responses that were topographically similar to nose poking were identified, even though there was no nose-poke device. Touching the nose to the wall where the nose-poke device had been previously installed was classified as "responses similar to nose poking," and it appears that nose-poking responses that had been strengthened in phase 1 competed with lever presses. Contingent subjects that concluded the first session in phase 2 faster than others under the same response effort condition (1CRF-C, 835"; 'FR-C, 837"; 3CRF-C, 1243 ") were the ones that emitted a smaller number of responses "similar to nose poking" (30, 28 and 17, respectively). Compared to the contingent subjects that required more time than others that had the same response effort (2FR-C, 2957", 2 CRF-C, 2021"), these subjects emitted a greater number of responses "similar to nose poking" (129 for both).

\section{Discussion}

This experiment did not identify a clear effect of a history of exposure to different conditions (contingent, noncontingent, and no exposure) on the acquisition of responses requiring different efforts, since the noncontingent condition did not systematically lead to a delay in response acquisition. There were also variabilities within and between conditions. The subjects that required the most time within their triads for response acquisition came from all three groups: noncontingent (3CRF-NC, 1FR-NC), contingent (2CRF-C) and control (1CRF-CT, $2 \mathrm{FR}-\mathrm{CT}$, and $3 \mathrm{FR}-\mathrm{CT}$ ). Likewise, subjects with the best performance within their triads came both from the noncontingent ( $1 \mathrm{CRF}-\mathrm{NC}, 2 \mathrm{CRF}-\mathrm{NC}$, and $2 \mathrm{FR}-\mathrm{NC}$ ) and contingent groups (3CRF-C, 1 FR-NC e $3 F R-N C$ ).

It is not uncommon for subjects exposed to CRF to present delays in response acquisition after exposure to noncontingent stimuli, seeing as other studies show the same result (Engberg et al., 1972; Job, 1988; Oakes et al., 1982; Schwartz et al., 1974; Welker, 1976). Welker (1976), who also compared response acquisition in CRF to that in FR3, also identified that some subjects exposed to CRF took longer to acquire the response, despite concluding, through statistical analysis, that FR 3 required more.

The present study did not demonstrate systematic differences between subjects from the CRF and FR conditions. These divergent data suggest that other 
conditions related to experimental conditions, as well as each subject's experimental history, have to be analyzed for us to understand these differences.

Beatty and Maki (1979), who applied a FR 3 schedule in phase 2 to reinforce lever presses by rats, also did not observe significant differences between noncontingent subjects and those with no exposure. It should be noted that, in contrast to the present study, the lever was present both in phase 1 and 2, during which lever-press response acquisition was assessed. Although the authors did not present data for lever presses in phase 1 of their study, some type of superstitious response pattern could have been selected among the noncontingent subjects in phase 1, which, in turn, could have facilitated the task in phase 2. Schwartz et al. (1974) had already suggested that the presence of the manipulandum across phases could facilitate the acquisition of a new response.

The present study sought to identify, by analyzing performance in phase 1 , variables that could be related to response acquisition by subjects with different experimental histories. According to Engberg et al. (1972) and Schwartz et al. (1974), competing responses strengthened in phase 1 can hinder response acquisition in phase 2 .

Video analysis of the last session in phase 1 for noncontingent subjects indicate responses that seem to have been maintained by noncontingent stimuli. Studies such as Cardoso et al. (2016) have shown the role of temporal contiguity in strengthening responses. Furthermore, these responses, strengthened by contiguity at the end of phase 1 , seem to have competed (reduced opportunities for emission) with lever presses in phase 2 since a high number of these responses were identified in that phase, especially before the acquisition of the new response. Engberg et al. (1972) do not adhere to this interpretation of their data, arguing that the chances of responses being accidentally reinforced would have been low since the stimuli were presented in a variable - and not fixed - time. In the present study, measuring other responses and their contiguities with appetitive events showed that it is possible for subjects to acquire such responses even when the stimuli are presented in a variable time.

This study did not present the same manipulandum in both phases, and the nose-poke device (manipulandum in phase 1) was also not used in phase 2. However, an elevated number of responses without delays were registered in both phases. These frequent responses were emitted in the experimental chamber 
(e.g., chamber ceiling, floor). Perhaps the use of the same chamber in both phases of this study made it possible for responses emitted in phase 1 to be evoked in phase 2.

Job (1988) mentions the occurrence of competing responses in contingent conditions due to the same experimental chamber being used in both phases. Oakes et al. (1981) used different chambers across phases and did not report competing responses by contingent and noncontingent subjects. The use of a different chamber in phase 2 could perhaps prevent contingent and noncontingent subjects from emitting such responses by controlling variables that possibly interfere in isolating the effects of these experimental conditions.

Studies using aversive stimuli present different hypotheses to explain the effect of exposure to noncontingent stimuli. Learned helplessness (Maier \& Sligman, 2016) establishes that subjects exposed to uncontrollable aversive stimuli can have difficulty learning an operant response. The data from the present study cannot be interpreted according to this hypothesis. Despite an "uncontrollable" condition having been planned for the presentation of water, all the noncontingent subjects emitted responses that were followed by the appetitive stimulus, which would prevent them from learning that events occurred regardless of their responses.

Another hypothesis proposed by studies using aversive stimuli is that of learned inactivity (Glazer \& Weiss, 1976), which establishes that the low level of activity found in subjects exposed to uncontrollable shocks is due to accidental contingencies: shock termination coincides with the moment in which the subject is still, and this accidentally selected pattern is incompatible with the task in phase 2. This hypothesis was discarded for logical reasons (Hunziker \& Gehm, 2010): if a pattern of low motor activity is accidentally selected by the punishment of high activity, then low activity would also be accidentally punished, causing the subject to consequently return to higher motor activity, and so forth. In the present study, all yoked subjects emitted a variety of responses, several of which were followed by noncontingent stimuli. Low motor activity was not identified in the presence of appetitive stimuli. The data indicate a high level of motor activity (Table 3.1), which had possibly been selected by noncontingent stimuli.

Another interpretation (Hunziker \& Gehm, 2010) suggests that helplessness depends on the contiguity present in the operant relation in phase 2 . There is a 
higher probability of helplessness if there is low contiguity (delayed reinforcer) and lower probability if there is high contiguity. Considering that, in phase 2 , one or three lever presses produced water without any delay, the planned contingency did not allow for this hypothesis to be tested. One could test this hypothesis with appetitive stimuli by establishing contingencies with different reinforcement delays in phase 2.

Another relevant discussion revolves around the use of a consumable stimulus such as water. As suggested by Capelari and Hunziker (2005), perhaps the difference in effects obtained by using aversive and consumable stimuli is due to the fact that the latter requires the subject to emit an additional response to access it (a condition in which the subject controls the stimulus), in contrast to a condition with uncontrollable shocks in which the subject has its paws on the floor. At the same time, one can argue that vision of water and the sound of the dispenser are uncontrollable stimuli. Future studies with non-consumable stimuli could investigate this issue. In phase 1 , for example, an unlocked activity wheel could serve as the reinforcer produced by nose poking. The response by contingent subjects would unlock the wheel for a defined amount of time or until the subject completed $X$ turns. For the noncontingent subjects, the apparatus would only unlock when the subject from the contingent group emitted the target response. In this manner, methodological aspects between studies using aversive and nonaversive stimuli would be more comparable.

Resolving these methodological issues could also have implications in applied contexts, in which there is a premise about the efficacy of using noncontingent reinforcement in the treatment of socially relevant behaviors (Moore et al., 2016; Phillips et al., 2017; Rooker et al., 2018). However, this statement needs to be treated with caution and not generalized to all cases. For example, there is evidence that the use of noncontingent reinforcement influences the efficiency of subsequent extinction procedures and the magnitude of the resurgence of inadequate behaviors (Lambert, Bloom, Samaha, Dayton, \& Kunnavatana, 2016). In addition, the use of noncontingent reinforcement, without the extinction of inadequate behaviors, can result in their resurgence when treatment is discontinued and no reinforcers are made available (Saini et al., 2017). In another study, resistance to extinction emerged as a result of noncontingent reinforcers being superimposed on a baseline schedule of reinforcement for 
problem behavior, a procedure occasionally used in applied contexts (Lieving, DeLeon, Carreau-Webster, Frank-Crawford, \& Triggs, 2018).

Data similar to those of the present study can be found in Kelley, Nadler, Rey, Cowie, and Podlesnik (2017). The authors conducted a translational study to verify the effects of noncontingent reinforcement at different densities on problem behavior and the acquisition of desirable alternative responses. As their main result, they found that the more the noncontingent reinforcer is presented, the more the target-behavior competes with the acquisition and maintenance of the alternative response. This result partly corroborates that of the present study, which seemed to show that responses strengthened by contiguous noncontingent stimuli competed, to a certain degree, with the lever-press response. Although reinforcer density was not manipulated in this case, it can be done in future research. Moreover, similarities observed between the effect of noncontingent reinforcement in both basic and applied research require further investigation and clarification in order to increase the effectiveness of technologies designed to treat socially relevant behavior.

\section{Final considerations}

The present study did not produce conclusive results regarding response effort in the acquisition of an operant response after exposure to noncontingent appetitive stimuli, as there was no consistency in the data from the noncontingent subjects. For some subjects, the contiguity between events in phase 1 seemed to have selected responses that influenced their performance in phase 2 since they continued to occur. Subjects that emitted a high number of other responses took longer to acquire the lever-press response than those that emitted few. This suggests that the delay reported in studies with appetitive stimuli could be generated by variables different to those associated with the delay in studies with aversive stimuli, which report a low frequency of responses by subjects from the noncontingent group.

Studies conducted with appetitive stimuli did not produce consistent results. The data of the present study indicate the importance of analyzing a subject's experimental history, including an analysis of changes produced in an organism's behavior in the phase in which it is exposed to noncontingent stimuli. The data also indicate that, in the planned conditions with subsequent appetitive events, a large 
number of responses are emitted by the noncontingent subjects in phase 1 , having been possibly selected by way of accidental contiguities, in contrast to the decrease in response frequency reported in studies using aversive stimuli. Further research needs to evaluate the extent of these conclusions.

Methodological refinements could help evaluate the possible generality of effects across studies using aversive and appetitive stimuli and could also help verify whether there are specificities pertaining to each type of noncontingent event: 1. measure, in addition to responses classified as the dependent variable, other responses that occur in phases 1 and 2, which could be acquired due to the contiguity between noncontingent events, seeing as the experimental history established in phase 1 could be related to performance in phase 2 ; 2 . use different experimental chambers across phases, in order to minimize control by the experimental context, which could be established in the first phase; 3 . evaluate the permanence of the possible effects, when identified, on the acquisition of the new response, assessing possible characteristics of the effects produced with aversive or appetitive stimuli, seeing as the effects regarding aversive stimuli seem to be more prolonged than those obtained with appetitive stimuli; and 4. whether aversive or non-aversive use non-consumable stimuli to facilitate the comparison between methodological aspects present in both types of studies.

\section{References}

Baum, W. M. (2017). Understanding behaviorism: Behavior, culture, and evolution. Malden: Wiley Blackwell.

Beatty, W. W., \& Maki, W. S. (1979). Acquisition of instrumental responding following noncontingent reinforcement: Failure to observe learned laziness in rats. Bulletin of the Psychonomic Society, 13, 268-271. doi:10.3758/BF03335079

Capelari, A., \& Hunziker, M. H. L. (2005). Aprendizagem de fuga após exposição a estímulos apetitivos incontroláveis. Psicologia: Teoria e Pesquisa, 21, 99-107.

Cardoso, L. A., Britto, I. A. G. S., \& Simonassi, L. E. (2016). Comportamento supersticioso em estudantes universitários. Revista Brasileira de Terapia Comportamental e Cognitiva, 18, 31-44. doi:10.31505/rbtcc.v18i1.829

Engberg, L. A., Hansen, G., Welker, R. L., \& Thomas, D. R. (1972). Acquisition of keypecking via autoshaping as a function of prior experience: "Learned Laziness"? Science, 178, 1002-1004. doi:10.1126/science.178.4064.1002 
Glazer, H., I., \& Weiss, J. M. (1976). Long-term interference effect: An alternative to "learned helplessness. Journal of Experimental Psychology: Animal Behavior Processes, 3, 202-213. doi:10.1037/0097-7403.2.3.202

Hunziker, M. H. L., \& Gehm, T. P. (2010). Uma nova interpretação sobre o desamparo aprendido. In E. Cillo, M. R. Garcia, P. Abreu, \& P. Faleiros (Orgs.), Sobre comportamento e cognição (Vol. 23, pp. 352-360). Santo André: ESETec.

Job, R. F. S. (1988). Interference and facilitation produced by noncontingent reinforcement in the appetitive situation. Animal Learning \& Behavior, 16, 451-460. doi:10.3758/ BF03209386

Kelley, M. E., Nadler, C. B., Rey, C., Cowie, S., \& Podlesnik, C. A. (2017). Noncontingent reinforcement competes with response performance. Journal of the Experimental Analysis of Behavior, 107, 343-353. doi:10.1002/jeab.255

Lambert, J. M., Bloom, S. E., Samaha, A. L., Dayton, E., \& Kunnavatana, S. S. (2016). Effects of noncontingent reinforcement on the persistence and resurgence of mild aggression. The Psychological Record, 66, 283-289. doi:10.1007/s40732-016-0170-7

Lieving, G. A., DeLeon, I. G., Carreau-Webster, A. B., Frank-Crawford, M. A., \& Triggs, M. M. (2018). Additional free reinforcers increase persistence of problem behavior in a clinical context: A partial replication of laboratory findings. Journal of the Experimental Analysis of Behavior, 109, 253-264. doi:10.1002/jeab.310

Maier, S. F., \& Seligman, M. E. P. (2016). Learned helplessness at fifty: Insights from neuroscience. Psychological Review, 123, 349-367. doi:10.1037/revoooo033

Moore, T. C., Robinson, C. C., Coleman, M. B., Cihak, D. F., \& Park, Y. (2016). Noncontingent reinforcement to improve classroom behavior of a student with developmental disability. Behavior Modification, 40, 640-657. doi:10.1177/0145445516629937

Oakes, W. F., Rosenblum, J. L., \& Fox, P. E. (1982). "Manna from heaven": The effect of noncontingent appetitive reinforcers on learning in rats. Bulletin of the Psychonomic Society, 19, 123-126. doi:10.3758/BF03330059

Phillips, C. L., lannaccone, J. A., Rooker, G. W., \& Hagopian, L. P. (2017). Noncontingent reinforcement for the treatment of severe problem behavior: An analysis of 27 consecutive applications. Journal of Applied Behavior Analysis, 49, 1-20. doi:10.1002/ jaba.376

Rooker, G. W., Bonner, A. C., Dillon, C. M., \& Zarcone J. R. (2018). Behavioral treatment of automatically reinforced SIB: 1982-2015. Journal of Applied Behavior Analysis, 51, 1-24. doi:10.1002/jaba.492 
Saini, V., Fisher, W. W., \& Pisman, M. D. (2017). Persistence during and resurgence following noncontingent reinforcement implemented with and without extinction. Journal of Applied Behavior Analysis, 50, 377-392. doi:10.1002/jaba.380

Schwartz, B., Reisberg, D., \& Vollmecke, T. (1974). Effects of treadle training on autoshaped keypecking: Learned laziness and learned industriousness or response competition? Bulletin of the Psychonomic Society, 3, 369-372. doi:10.3758/BF03333501

Skinner, B. F. (1948). "Superstition" in the pigeon. Journal of the Experimental Psychology, 38, 168-172. doi:10.1037/0096-345.121.3.273

Welker, R. L. (1976). Acquisition of a free operant appetitive response in pigeons as a function of prior experience with response independent food. Learning and Motivation, 7, 394-405. doi:10.1016/0023-9690(76)90045-X

\section{Authors notes}

Carlos Henrique S. da Silva, Postgraduate Studies Program in Experimental Psychology: Behavior Analysis (PEXP), Pontifical Catholic University of São Paulo (PUC-SP); Nilza Micheletto, Postgraduate Studies Program in Experimental Psychology: Behavior Analysis (PEXP), Pontifical Catholic University of São Paulo (PUC-SP).

This research was partially founded by CAPES.

Correspondence concerning this article should be addressed to Carlos Henrique Santos da Silva, Rua Bartira, 387, Perdizes, São Paulo, SP, Brasil. CEP 05009-000.

E-mail: rriques@gmail.com 